\title{
Endoscopic management of a difficult common bile duct stone
}

\section{A H Liyanage ${ }^{1}$, Y Sadakari ${ }^{1}$, J lenaga ${ }^{1}$, R Tanabe ${ }^{1}$, S Takahata ${ }^{1}$ and M Tanaka ${ }^{1}$}

Key words: ERCP, sphincterotomy, CBD stone, lithotripsy

\section{Introduction}

Endoscopic sphincterotomy and lithotripsy using a lithotripter basket have evolved as successful methods to manage bile duct stones. Endoscopic methods reduce morbidity associated with open or laparoscopic surgery. A major deterrent to successful endoscopic management of bile duct stones is large size, especially if the diameter of the stone is greater than the basket. We report a patient who had recurrent common bile duct (CBD) and hepatic duct stones, with one stone in the CBD measuring $35 \mathrm{~mm}$ $\times 33 \mathrm{~mm}$, and the endoscopic technique used to clear the CBD.

\section{Case report}

A 75-year old man, with an ASA (American Society of Anaesthesia) grading of 3, who had a history of recurrent choledocho / hepaticolithiasis presented with one large stone $(35 \mathrm{~mm} \times 33 \mathrm{~mm})$ and multiple smaller stones in he CBD. He underwent endoscopic retrograde cholangiopancreaticography (ERCP). The large stone was in the upper $\mathrm{CBD}$ at the hepatic duct confluence and there were three free floating $10 \mathrm{~mm}$ stones in the distal dilated segment (figure 1). After deep canulation, an Olympus BML -2q lithotripter (Olympus Optical Co. Tokyo, Japan) was advanced along a guide-wire beyond the large stone. The largest available basket $(31 \mathrm{~mm})$, would not accommodate the whole stone. The technique we used to break this stone was to grate the edge of the stone, which resulted in its disintegration. Thereafter the stone was partially held with the basket and piecemeal crushing was done with periodic evacuation into the duodenum. With multiple such passages it was fluoroscopically confirmed that complete clearance had been achieved (figure 2). The stone was a pigment stone that could be crushed easily. The CBD was stented with two $8.5 \mathrm{Fr}, 7 \mathrm{~cm}$ stents to facilitate free drainage of bile, and to prevent cholangitis (figure 3). The patient made an uneventful recovery.

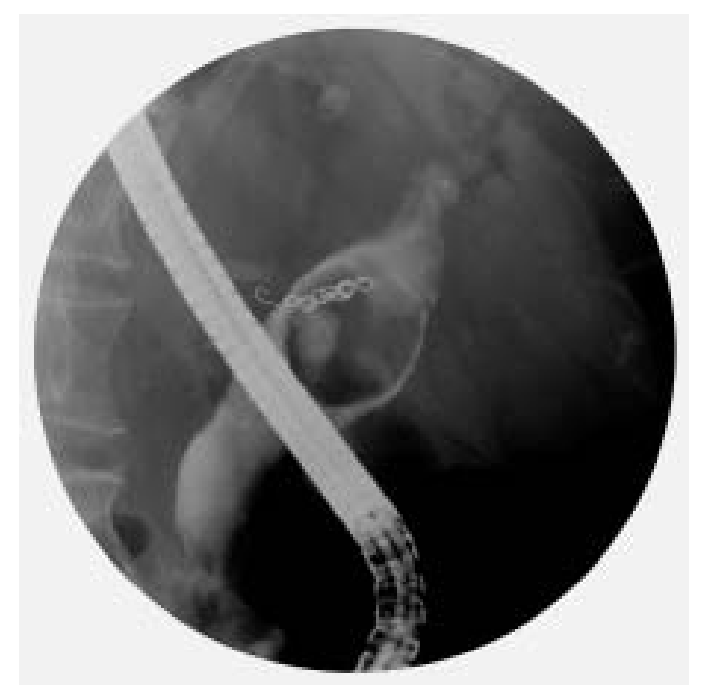

Figure 1. ERCP finding of large proximal CBD stone and distal small stones. (Note: the size of the scope is $1.7 \mathrm{~cm}$ )

${ }^{1}$ ERCP Laboratory, Department of Surgery 1, Graduate School of Medicine, Kyushu University Hospital, Fukuoka 812-8582, Japan.

Correspondence: CAHL, e-mail <chandikaliyanage@hotmail.com>. Competing interests: none declared. Received 8 October 2007 and revised version accepted 23 May 2008. 


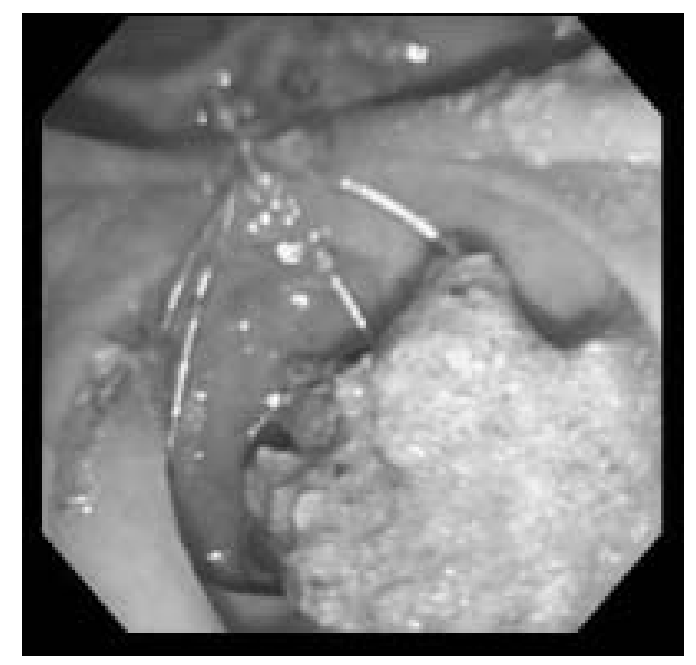

Figure 2. Basket evacuating the crushed stone.

\section{Discussion}

Since it was first introduced in 1982, mechanical lithotripsy, more CBD stones are treated endoscopically [1]. Many endoscopists claim that stones larger than the lithotripter basket are best managed by non-endoscopic techniques such as extracorporeal shock wave lithotripsy (ESWL) or surgery [2]. However, our patient had an unfavorable ASA grade and a previous history of procedure related complications. The grating of the side wall, partial grasping of the stone, and then crushing it piecemeal was the method we successfully used in this difficult case. In these situations it is important to remove the stones completely to avoid reformation [3].

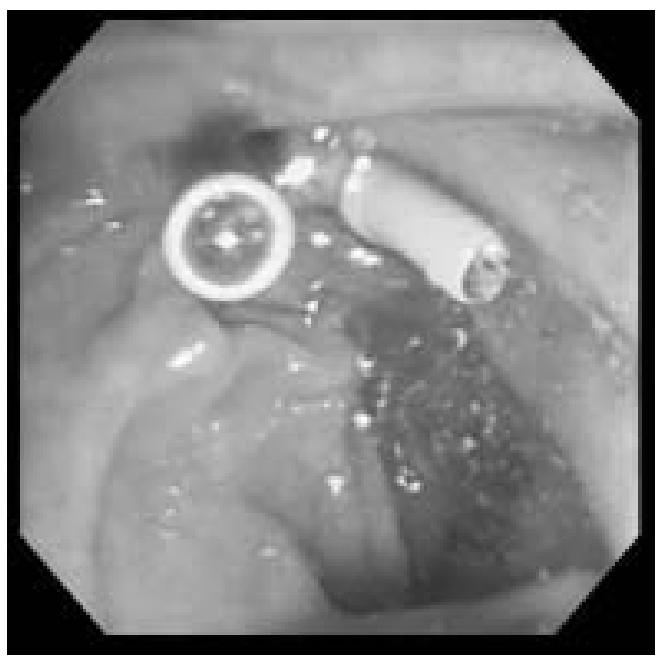

Figure 3. Double stenting of the CBD.

\section{References}

1. Riemann JF, Seuberth K, Demling L. Clinical application of a new mechanical lithotripter for smashing common bile duct stones. Endoscopy 1982; 14: 226-30

2. Hochberger J, Tex S, Maiss J, Hahn EG. Management of difficult common bile duct stones. Gastrointestinal Endoscopic Clinics of North America 2003;13: 623-34.

3. Sand J, Airo I, Hiltunen KM, Mattila J, Nordback I. Changes in biliary bacteria after endoscopic cholangiography and sphincterotomy. American Surgeon 1992; 58: $324-8$. 